\title{
A Corpus-based Contrastive Analysis of First Personal Deixis
}

\author{
Yujie $\mathrm{Su}$ \\ College of Foreign Studies, Wenzhou University, Wenzhou 325035, China \\ Email: susanwtf@yahoo.com.cn
}

\begin{abstract}
This paper centers on comparing the use of first personal deixis in Chinese English Learner Corpus (CLEC) and English-native Speaker Corpus such as FROWN and FLOB. It also makes a close investigation into the frequency difference of first nominative personal deixis, that is, "I" and "we", and their practical use with modal verbs in the three corpora. Based on the results of the comparison and investigation of the uses of "I" and "we", the writer tries to look into the reasons which cause the difference in order to enlighten English teaching in Chinese English learners' classes.
\end{abstract}

Index Terms - first personal deixis, modal verbs

\section{INTRODUCTION}

Chinese English learners, advanced or primary, are usually unconsciously influenced by their mother language when learning and using English. They often prefer to use the first personal deixis like "I" or "we" and other alternative forms like "me", "us", "my", "our", and so on. Having this in mind, the writer wants to find out the underlying reason so that an investigation into three corpora, Chinese English Learner Corpus, FROWN and FLOB, is conducted and comparison of the frequency of the nominative first personal deixis, that is "I" and "we", as well as the frequency of their practical use with modal verbs in the three corpora is also made. It turns out that comparing with English native speakers, Chinese learners tend to show their distinctive preference when using the first personal deixis.

\section{COMPARISON AND ANALYSIS OF ENGLISH LEARNERS AND NATIVE SPEAKERS CORPORA}

Chinese English Learner Corpus (CLEC), sponsored and constructed by Professor Gui Shichun from Guangdong University of Foreign studies, contains 1 million words of English compositions collected from Chinese learners of English with differing levels of proficiency, covering senior secondary school students, English-major, and non-English-major university students in China. Freiburg-LOB Corpus of British English and Freiburg-Brown Corpus of American English, also known as FLOB and FROWN, are corpora of English native speakers, each containing 1 million words. Essentially, comparison between the corpora of English learners and native speakers with particular purpose can help to learn about the different way of expression, like the overuse or underuse of certain words or expressions as well as learner's difficulty when learning or using the language. And also, the results obtained by comparing and analyzing the data of the corpora of learners and native speakers are comparatively objective and scientific, which is practically useful for studying learners' learning strategy and getting teachers of the language to notice learners' difficulties or problems.

In English, there is a distinction between nominative and accusative first personal deixis, such as "I" and "me", "we" and "us". Their possessive forms are respectively "myself, my" and "ourselves, our". However, in Chinese there is only a division between the singular form and plural form of the nominative and accusative first personal deixis. Comparing with the different variations in English, Chinese first personal deixis has fewer and simpler changes. Through investigations of how the first personal deixis is used into the three different corpora, we can see the results in Table One, which is arranged by keyness.

TABLE 1

THE FREQUENCY OF THE FIRST PERSONAL DEIXIS IN CLEC, FLOB AND FROWN

\begin{tabular}{|c|c|c|c|}
\hline Frequency & CLEC & FLOB & FROWN \\
\hline first personal deixis & & & \\
\hline we & & & 2,888 \\
\hline I & 13,356 & 2,703 & 6,910 \\
\hline my & 16,216 & 6,115 & 1,959 \\
\hline our & 6,272 & 1,572 & 1,156 \\
\hline us & 4,774 & 991 & 788 \\
\hline me & 2,546 & 806 & 1,520 \\
\hline myself & 2,712 & 1,307 & $/$ \\
\hline
\end{tabular}

Seen in the table above, though CLEC is a corpus which is smaller than FLOB and FROWN, it is clear that the 
singular forms of the first personal deixis are much more frequently used by learners than their plural forms. What's more, Chinese English learners are more often to use "I" and "we". The frequency of "I" in CLEC is 16,216, which is almost 3 times larger than that in FLOB and FROWN. The frequency of "we" in CLEC is more than 6 times higher than that in FLOB and FROWN. Generally speaking, the frequency of other forms of the first personal deixis in the learner corpus is far higher than that in English-speaker corpora.

In order to know more about the phenomena, detailed investigations are conducted. By means of the software WORDSMITH, modal verbs which Chinese English learners prefer to use together with "we" and "I" are searched according to the key word in context. It is found that the modal verb "must" is used most often, followed by "will", "would", "shall", "can", "should", "may", etc. For an objective knowledge of how the plural and singular form is used with those modal verbs, a comparison among the three corpora, CLEC, FLOB and FROWN, is conducted. The results can be seen in Table Two and Table Three.

TABLE 2

COMPARISON OF “WE+MODAL VERBS" IN CLEC, FLOB AND FROWN

\begin{tabular}{|c|c|c|c|}
\hline we + modal verbs & CLEC & FLOB & FROWN \\
\hline we can/can't & $2251+348$ & $124+37$ & $140+24$ \\
\hline we could/couldn't & $152+67$ & $53+5$ & $58+7$ \\
\hline we may & 145 & 43 & 29 \\
\hline we might & 13 & 27 & $59+0$ \\
\hline we must/mustn't & $1072+19$ & $65+0$ & 7 \\
\hline we ought (to) & 34 & 6 & 32 \\
\hline we shall & 82 & 64 & $45+0$ \\
\hline we should/shouldn't & $1395+37$ & $60+1$ & $165+6$ \\
\hline we will+won't & $705+16$ & $130+2$ & $84+5$ \\
\hline we would/wouldn't & $135+9$ & $77+3$ & \\
\hline
\end{tabular}

TABLE 3

COMPARISON OF “I+MODAL VERBS” IN CLEC, FLOB AND FROWN

\begin{tabular}{|c|c|c|c|}
\hline I+ modal verbs & CLEC & FLOB & FROWN \\
\hline I can/can't & $709+198$ & $110+107$ & $154+103$ \\
\hline I could/couldn't & $249+118$ & $144+38$ & $151+50$ \\
\hline I may & 46 & 20 & 39 \\
\hline I might & 9 & 25 & $37+3$ \\
\hline I must/mustn't & $393+0$ & $48+1$ & 1 \\
\hline I ought to & 10 & 9 & 31 \\
\hline I shall & 26 & 71 & $367+24$ \\
\hline I should/shouldn't & $206+8$ & $70+5$ & $262+25$ \\
\hline I will/won't & $1092+14$ & $279+16$ & $130+23$ \\
\hline I would/wouldn't & $397+11$ & & \\
\hline
\end{tabular}

In Table Two, the frequency of the three combinations like "we+can", "we+should" and "we+must" is particularly high. The frequency of "we+can" and "we+must" in CLEC is almost up to twenty times of that in FLOB and FROWN, while the frequency of "we+should" in CLEC is twenty-three times as high as that in FLOB and FROWN. Except the combination "we+might" showing the greatest uncertainty, the other "we+modal verbs" combinations are popularly used, whose frequency exceeds that in the English-speaker corpora.

Though the contrast of the three corpora in Table Three is not so strong as that in Table Two, it is still clear to see that Chinese English learners are most likely to use the combinations like "I +will", "I+can" and so on, which emphasize the speakers' intention. The frequency of "I+will" in CLEC is 1092, which is two or three times higher than that in FLOB and FROWN, and the frequency of "I+can" is up to four or six times higher.

Then compared with the two tables, Chinese English learners tend to use the plural form of the first personal deixis, for only two combinations like "I+could" and "I+will" have higher frequency than "we+could" and "we+will".

\section{ANALYSIS OF THE DATA AND THE POSSIBLE REASONS}

Generally speaking, personal deixis refers to the terms the speakers use to convey their message with the words when they call each other during the conversation. There are three types: the first personal deixis, the second deixis and the third deixis. Chinese and English have a similar division of the personal deixis. However, as for the first personal deixis, the alleged scope in Chinese and English is different, as Wei Benli has concluded in his research on The Cultural Metaphor of First Person Deixis in Chinese and English. There are also many other researchers like Wang Lifei and Wen Qiufang (2004), Zhong Zhihua (2007), Zhou Lei and Niu Zhongguang (2007), and so on who have conducted various studies on personal deixis. Most of their researches is centered on cultural aspects.

In English the singular first personal deixis "I" can be used in formal and informal contexts, which has a clear and specific referent. In English, the first person "I" generally refers to the speaker himself or herself, expressing his or her own views. It seldom includes the listener. This is similar to the first person in Chinese. The plural first person "we" in Chinese has a similar alleged scope as that in English, which refers to the speaker's side or both the speaker and the 
listener. But in conversations when the speaker and the listener are from different ranks, or the speaker wants to persuade or encourage the listener, "we" can be used to refer to the listener. "we" can also refer to the speaker only. For example, one of the staff says to a friend who does not work at the same department, "We have a kind leader." Here in this sentence "we" refers to the speaker only. However, "we" in English, when referring to the speaker himself or herself, carries the sense of authority, producing an estranged feeling between the speaker and the listener, and showing the speakers lacking enough confidence in what he or she says.

According to what researchers like Hofstede (2002)and Triandis (1995)have found out, China is a country with a collectivist culture, which encourages the development of group identities by teaching communal sensitivity and cooperation, gives priority to the goals of one's groups and emphasizes on the harmonious and equal relations, and social responsibility of the group members. Countries like Britain and US have individualist culture, which gives priority to one's own goals and defines one's identity in terms of personal attributes. According to Triandis, English speakers tend to pay a high attention to their own freedom, independency and value. Chinese English learners are frequently under the influence of traditional Chinese culture and values, preferring to use the collective "we" to represent an individual "I". The reason is that the use of "I" means the feeling when one is isolated from the collective or one endangers the unity of the community. That is why the individual "I" is basically excluded from the collective written culture affected by Confucianism, Taoism, and Buddhism. On the contrary, plural forms of the first personal deixis are much welcomed. Therefore, as for Chinese English learners, the use of the collective "we" can help bring both sides of the communication closer to each other and build an equal and friendly relation. So in their writing they often use "we will", "we must", "we can", etc.

The results also explain that the Chinese learners tend to use spoken language where written language should be used. Wen Qiufang and other researchers (2003) have conducted studies on the colloquial trend in written language among university learners. They have found that Chinese English learners, like other non-English-native speakers, overemphasize the marked existence of readers or writers in their writing. That is to say, the higher the prominence of the writer is, the more colloquial the language is.

The reasons behind the different using habit of the first personal deixis first go to the difference between the two languages and then lie in the fact that in China English teaching has its innate defects. Cheng Zhenglun and Tang Ping (2007) have found that regardless the English proficiency of English learners, they just get to know the language itself, but not the cognition and cultural values of the community which take English as their mother tongue. In other words, in China English is only used or learned as a foreign language. In English classes English is mainly taught by teachers whose first language is Chinese, and who used to be English learners themselves. And the teachers learned the language in a traditional Chinese teaching system. As a result, they often teach what they deem to be true or right.

\section{CONCLUSION}

English and Chinese belong to different language systems. English learners are inevitably under the influence of their mother tongue. In order to reduce the negative transfer of the mother tongue, the teachers may make use of various corpora and explain to the students the different cognition of the first personal deixis of English-native speakers and English learners by show them the particular examples. The contrastive analysis of both the English learner corpus and the English native speaker corpus can help the students to understand better so that they can be aware of the negative transfer of Chinese when they say or write something.

\section{REFERENCES}

[1] Chen, Zhenglun \& Tang, Ping. (2007). The Influence of Collectivism on English Writing — Case Study of Personal Deixis. Journal of Sichuan College of Education 3, 86-88.

[2] Hofstede, Geert. (2002). Dimensionalizing Cultures: The Hofstede Model in Context. http://www.ac.wwu.edu/ culture/hofstede.htm (accessed 20/3/2009)

[3] Triandis, H. C. (1995). Individualism \& Collectivism. Boulder, CO: Westview Press.

[4] Wang, Lifei \& Wen, Qiufang. (2004). Transference of Mother Tongue Proficiency on Second Language Writing: the Methodology and Path Analysis of Crosslanguage. Foreign Language Teaching and Research 36, 205-212.

[5] Wei, Benli. (2002). The Cultural Metaphor of First Person Deixis in Chinese and English. Shandong Foreign Languages Journal 6, 78-80.

[6] Wen, Qiufang, Ding, Yanren \& Wang, Wenyu. (2003). Features of oral style in English compositions of advanced Chinese EFL learners: An exploratory study by contrastive learner corpus analysis. Foreign Language Teaching and Research 4, 268-276.

[7] Zhong, Zhihua. (2007). Communicative Function and Cultural Difference of the Plural English and Chinese First Deixis. Journal of Liaoning Administration College 12, 175-176.

[8] Zhou, Lei \& Niu, Zhongguang. (2007). Analysis of First Personal Deixis Projection from Pragmatic Distance Perspective. Journal of Chongqing Institute of Technology 21, 168-170. 
Yujie Su was born in Wenzhou, China in 1978. She received her M.A. degree in Foreign Languages and Applied Linguistics from Guangdong University of Foreign Studies, Guangzhou, China in 2009.

She started her career as an English teacher in Zhejiang College of Industries and Technologies after beautiful accomplishment of four-year study and graduation from Zhejiang University in June of 2001. Since the August of 2002 she was transferred to Wenzhou Normal College and pursued her career as an English teacher. In 2007 she entered Guangdong University of Foreign Studies for her M.A. degree. Up to now she has published almost 10 research papers in journals. Her research interests include English teaching, translation and lexicography.

$\mathrm{Ms} \mathrm{Su}$ is a member of College of Foreign Languages in Wenzhou University. 